\title{
Pablo Gómez
}

The Experimental Caribbean: Creating Knowledge and Healing in the Early Modern Atlantic (Chapel Hill, NC: University of North Carolina Press, 2017), pp. 314, \$29.95 (paperback), IsBN 9781469630878.

Histories of science and medicine in the early modern era have often had little to say about non-European creators of knowledge. While many studies note that European natural philosophers absorbed African or indigenous ideas about the natural world they encountered in the Americas, in most accounts, even those highlighting the role of Native or African informants, Europeans ultimately legitimized such information in colonial or metropolitan centers of learning, and thus were the ones who created 'real' scientific knowledge. In this rich and rewarding book, Pablo Gómez directly challenges this view, arguing that African and Afro-Caribbean healers in the Spanish Caribbean created their own new and distinct ideas about the body, health, and medicine. Gómez's arguments emerge from a truly impressive research foundation - he has worked in numerous archives on three continents - including a series of remarkable documents from the Inquisition Office in Cartagena de Indias, many of them previously unknown to or unused by scholars. In this material, Gómez has identified 102 black healers (whom he frequently calls 'Mohanes,' a Native American term that first appeared in sixteenth-century records). These healers - male and female, some enslaved, but most free - fused various West African conceptions of the natural world with their own experiences and encounters with Native Americans and Europeans, and with the natural world of the Caribbean basin, to forge new tools to both comprehend and utilize the environments in which they found themselves. Unlike Europeans, whose search for knowledge built upon the work of the ancients, Gómez argues, black healers had little time for "first principles, tradition, or dogma." Instead their knowledge came from "experiential phenomena they manufactured anew on the basis of localized circumstances in different Caribbean locales" (p. 3). An increased emphasis on experience was, of course, also a key attribute of the "new science' gathering momentum in Europe during the seventeenth century. Gómez notes that knowledge production in the Caribbean occurred alongside these efforts and often overlapped with them, but he emphasizes the distinctiveness and creativity of the region's black healers who, he suggests, worked in vastly different social and intellectual worlds.

The book's first three chapters provide background and context for understanding the place of black healers in the Spanish Caribbean. The first chapter looks at the region's demography, highlighting the diversity of African peoples who arrived during the long seventeenth century (1580-1720) and their 
experiences thereafter. The analysis focuses on urban areas, where many of these healers lived and operated. As Gómez notes, these cities were far removed from the "rigid and hierarchal" world of the plantation zone that has attracted the greatest attention from Caribbean scholars (p. 23). The second chapter highlights the region's disease environment. Gómez deliberately avoids linking early modern descriptions of disease to modern Western classifications, arguing that "people lived in very different bodies in the past. They also suffered differently from different illnesses (even if seemingly caused by the same agents)" (p. 40). Chapter 3 explores the movement of healers and ideas about healing around the Caribbean basin. Here Gómez emphasizes the fluidity of knowledge and information, suggesting that attempts to classify ideas as originating with one particular group or another fail to capture the novelty of black healers' engagement with overlapping traditions and with different environments, and the extent to which even familiar rituals and practices took on new meanings in these contexts.

Chapters 4 through 7 explore the processes by which back healers made sense of these new worlds. Chapter 4 struck me as particularly interesting. It examines the sensory world of the Caribbean, arguing that healers sensed the world differently - they smelled and felt and saw things that others did not and by doing so, created new understandings of the physical world itself. Rather than seeing such healers and their methods as 'exotic' or dissimilar to other (i.e. European) intellectual pursuits, Gómez argues that they represented a distinct form of engagement with the natural (and spiritual) world, and that for many of the region's residents, black practitioners were the ones who "classified, explained, and defined the nature of how bodies worked, what could be sensed, and the experiences around which these realities could be described" (p. 117). As becomes clear in the subsequent three chapters, Mohanes knowledge of the natural world and the use of that knowledge was not limited to the bodies of other Africans and Afro-Caribbeans. Clients also included Native Americans and numerous Spaniards, including local officials and Catholic priests. Indeed, as Gómez makes clear, a competitive marketplace in healing existed throughout the region during this period. What mattered most for patients was effectiveness, and effectiveness came from experience with the Caribbean world. Thus Gómez outlines stories of a Catholic priest who hired an African healer to treat a Native American women in his mission, and of the Bishop of Cartagena, who was treated for several months by a former slave woman from Cuba serving a life sentence for witchcraft. In the end, scientific "truth" in the Spanish Caribbean emerged from "novel ways of thinking about the senses, the experiential, and the 'interchangeability of knowledge'" (p. 188). 
Inherited traditions and knowledge mattered less than what people experienced in their immediate circumstances.

This is a fascinating and challenging book that will reward readers in a variety of fields, including the history of early modern science and medicine, but also those interested in the broader social and intellectual history of the Caribbean and the Atlantic world. The materials and stories that Gómez has unearthed provide a unique and invaluable perspective on the complex everyday world of the Spanish Caribbean at a time when residents grappled with basic issues of health and welfare. That said, some readers may struggle with individual parts of the book. While Gómez's narratives of individual case studies are clear and engrossing, at times his writing can be dense and jargony. I also wondered about the outcomes of some of the cases analyzed. We know about these healers because they were hauled before the Inquisition, often multiple times (and sometimes because they were denounced by fellow practitioners). Presumably in some of these cases the activities of healers, regardless of their medical effectiveness, crossed a line that Spanish authorities did not tolerate. What happened in those cases? What happened to the two slaves who "tied" the legs of their owner, rendering him "crippled," for example? We know the owner remained unable to use his legs, but what happened to the slaves? Did they truly reverse the power relationship, as Gómez suggests, or were they punished for the challenge? Likewise, there must be some cases in which the healers' actions proved ineffective: what happened in those cases? Black healers clearly posed powerful challenges to European intellectual traditions, hierarchies, and institutions, and while the fate of individual healers is not Gómez's primary concern, knowing the outcome of some cases (when possible) would help assess the place and impact of black healers in the region at various times, and across time.

Such comments notwithstanding, the rich material Gómez has uncovered in Inquisition records provides powerful testimony to the "creativity, adaptability, and rich intellects of early modern Caribbean people" (p. 15). His innovative and deeply reflective analysis of those records is certain to inform a new generation of scholarship in several fields.

\section{Matthew Mulcahy}

Loyola University Maryland mmulcahy@loyola.edu 